\title{
0 teste de sensibilidade à feniltiocarbamida (PTC) usado como prática lúdica no ensino de genética
}

\author{
Ingrid de Souza Freire \\ Fernanda Costa Vinhaes de Lima²
}

\section{Resumo}

O ensino de genética sempre foi um desafio para lecionadores. O objetivo deste trabalho foi aproximar as bases conceituais da genética ao cotidiano dos indivíduos, utilizando como método pedagógico o teste de sensibilidade à feniltiocarbamida. A diluição da feniltiocarbamida em quinze soluções com gradientes decrescentes de concentração ocorreu de acordo com Fox (1932). A prática foi desenvolvida em dois centros educacionais. Foram incluídos 154 participantes, dos quais 5,2\% eram fumantes, e 90,3\% sensíveis à feniltiocarbamida. A percepção ao amargo concentrou-se entre as soluções sete, oito e nove, com $48 \%$ dos indivíduos analisados, mas foi na solução oito que a maioria $(20,15 \%)$ percebeu o gosto amargo da proteína. Nenhum participante mostrou sensibilidade à feniltiocarbamida na solução quinze. Para a população em estudo, a frequência do alelo recessivo é de 0,31 . A relação entre indivíduos fumantes, gripados e a capacidade de sentir o gosto não foi significativa.

Palavras-chave: Proteína. Polimorfismo. Paladar. Educação.

\section{Introdução}

Os grandes avanços científicos que ocorreram recentemente na área da Biologia, especialmente na Genética, geraram um volume muito grande de novas informações e de conhecimentos mais complexos nesta área (VILAS-BOAS, 2006).

\footnotetext{
${ }^{1}$ Graduada em Biologia pelo Centro Universitário de Brasília - UniCEUB. ingridbiomol@ gmail.com

${ }^{2}$ Professora de Genética da FACES do Centro Universitário de Brasília - UniCEUB. fvlima@ solar.com.br
} 
Por isso, quando se trata de temas como clonagem, testes de exclusão de paternidade, células tronco, doenças e/ou características fenotípicas expressas geneticamente, a população leiga enfrenta inúmeros questionamentos, sobretudo de alunos de ensino fundamental, médio, educação de jovens e adultos (EJA) que ainda estão construindo uma base conceitual-científica sobre genética.

Para tornar as aulas e o aprendizado em genética mais dinâmico e participativo, torna-se fundamental a utilização de jogos, como os de dominó, peças de teatro e experimentos que facilitem conceitos importantes de Genética (RAMALHO et al., 2006; BERNARDES, 2007).

O lóbulo da orelha aderente ou solto, herança da cor dos olhos e da pele, são exemplos que auxiliam a correlação da Genética ao cotidiano (CAMARGO; INFANTE-MALACHIAS, 2007). Alguns aspectos, como o paladar, que seleciona os alimentos e influencia diretamente na saúde do homem, podem ser mencionados a fim de despertar o interesse maior dos alunos. Sabe-se que a percepção do paladar para algumas proteínas está associada ao genótipo de cada indivíduo, e que variantes alélicas podem proporcionar diferentes percepções para o sabor.

Compostos químicos como fenol, polifenol, ureias, tioureias, peptídeos e aminoácidos são alguns dos responsáveis pelo gosto amargo encontrado em certos alimentos. Proteínas como a feniltiocarbamida (PTC) e o 6-n-propiltiouracil, ao serem ingeridas, provocam um gosto amargo em algumas pessoas. Esse traço mendeliano é determinado por um gene dominante que é passado de pais para filhos (DREWNOWSKI et al., 2001).

A PTC é encontrada em vegetais da família Cruciferae ou Brassicaceae, constituída por exemplo pelo brócolis, couve, couve-de-bruxelas, couve-flor, agrião e repolho. Ela também pode ser encontrada em pimenta, chá verde, vinho tinto e em gramas e capins da família Gramineae (DREWNOWSKI et al., 2001).

O gene que condiciona o gosto amargo do PTC TAS2R38 está localizado no braço longo do cromossomo 7 (7q35-q36), e contém cerca de 1.002 pares de base (pb) em sua região codificadora (KIM et al., 2003; WOODING et al., 2004; MERRITT et al., 2008).

O gene TAS2R38, pertencente à família dos receptores para o amargo TAS2R, apresenta cinco formas alélicas, onde uma delas ( $\mathrm{t}$ ) condiciona a insensi- 
bilidade, sendo recessiva em relação aos outros alelos. Assim, indivíduos que são insensíveis possuem genótipo homozigoto recessivo, tt. As outras quatro formas alélicas (T1, T2, T3 e T4) determinam uma expressividade variável entre os indivíduos sensíveis (KIM et al., 2003; MORAIS et al., 2007; MERRITT et al., 2008). Contudo, a distinção entre sensíveis e supersensíveis está apenas relacionada a fatores ambientais (DREWNOWSKI et al., 2001).

Inúmeros estudos relacionam certas doenças como esquizofrenia, epilepsia, psicoses e doença de Parkinson com a percepção à PTC (KARAM-JUNIOR, 1975; MOBERG et al., 2005; MOBERG et al., 2007). Além disso, a proteína já foi usada como marcador genético em indivíduos depressivos (WHITTEMORE, 1986).

A sensibilidade à proteína feniltiocarbamida tem sido uma ferramenta comumente usada em estudos de evolução, seleção natural, e percepções gustativas (KIM et al., 2006; WOODING, 2006).

Análises moleculares do gene TAS2R38 mostraram que a diferença entre indivíduos insensíveis e sensíveis está na mudança de algumas bases nitrogenadas desse gene. Mudanças de uma única base podem alterar toda estrutura de uma molécula, ou mesmo o aminoácido a ser produzido. Nesse caso, a diferença entre pessoas sensíveis e insensíveis ao PTC está na mudança de apenas três aminoácidos. Quando essas mutações ocorrem em um único nucleotídeo, são conhecidas como Polimorfismo de Nucleotídeo Único (SNPs).

Nas escolas, a prática pedagógica torna-se um auxílio na complementação da aula. Os alunos observam na prática como a teoria funciona e como características genéticas podem inferir em sua dieta e/ou saúde.

Baseando-se no histórico científico da educação no Brasil, cujas práticas pedagógicas foram recentemente implantadas, novas metodologias de ensino que tenham como interesse disseminar a cultura e tecnologia se sobressaem em meio ao caos educacional que determinadas comunidades brasileiras vivem.

O presente trabalho teve como objetivo aproximar as bases conceituais da genética ao cotidiano dos indivíduos, utilizando como método pedagógico o teste de sensibilidade à feniltiocarbamida (PTC), adicionando informações que, muitos desses, não imaginam estar relacionadas à Genética. 


\section{Metodologia}

O teste do PTC, consiste em experimentar uma solução composta por água e a referida proteína, feniltiocarbamida, comumente encontrada em vegetais que fazem parte de uma dieta alimentar saudável (DREWNOWSKI et al., 2001).

O protocolo adotado para a diluição da feniltiocarbamida em quinze soluções, com gradientes decrescentes de concentração foi de acordo com Fox (1932). Essas soluções foram mantidas em frascos conta-gotas e armazenadas em geladeira.

O experimento envolveu 154 indivíduos, entre eles, 96 eram alunos dos cursos de Biomedicina e Biologia do Centro Universitário de Brasília, e 58 eram alunos e professores do Centro Educacional 02 de Taguatinga.

Após aprovação do comitê de ética em pesquisa com seres humanos do UniCEUB, a prática foi devidamente autorizada pelos responsáveis acadêmicos das duas instituições anteriormente citadas.

Foram pingadas cerca de duas gotas na língua de cada participante de maneira crescente em concentração da proteína, até o momento que o indivíduo constatasse o gosto amargo da proteína. Quando necessário, o procedimento era repetido afim de confirmar a percepção à feniltiocarbamida.

Posteriormente, procedeu-se o preenchimento de um questionário anônimo (anexo 1) com informações como idade, sexo, hábito tabagista, infecções recentes e o número da solução que o indivíduo percebeu o gosto da feniltiocarbamida. O questionário apresentava também, vários alimentos que contêm feniltiocarbamida e os participantes assinalaram de quais eles gostavam, não gostavam ou não conheciam. Estas informações se fazem necessárias uma vez que pesquisadores as tentam relacionar com a percepção à proteína.

\section{Resultados}

De 154 participantes, $62,3 \%(\mathrm{n}=96)$ eram do sexo feminino e $37,7 \%$ do sexo masculino. A população foi caracteristicamente jovem, com faixa etária de 18 a 20 anos. Grande parte dos participantes com idade superior/igual a 41 anos $(7,1 \%)$ faziam parte do corpo docente da escola pública. 
A sensibilidade à feniltiocarbamida prevaleceu na solução de número 08 com 20,1\% dos participantes, conforme ilustra a figura 1 . De 90,3\% dos indivíduos sensíveis, $14,3 \%(\mathrm{n}=22)$ sentiram na solução $09,13,6 \%$ na $07,7,8 \%$ nas 06 e 10, 4,5\% na 11, 3,9\% nas 03 e $05,3,2 \%$ nas 04 e 12, e 1,9\% nas soluções 01 , 02,13 e 14. Nenhum participante mostrou sensibilidade à feniltiocarbamida na solução quinze.

Figura 1 - Distribuição dos participantes quanto a sensibilidade à feniltiocarbamida (PTC) por solução.

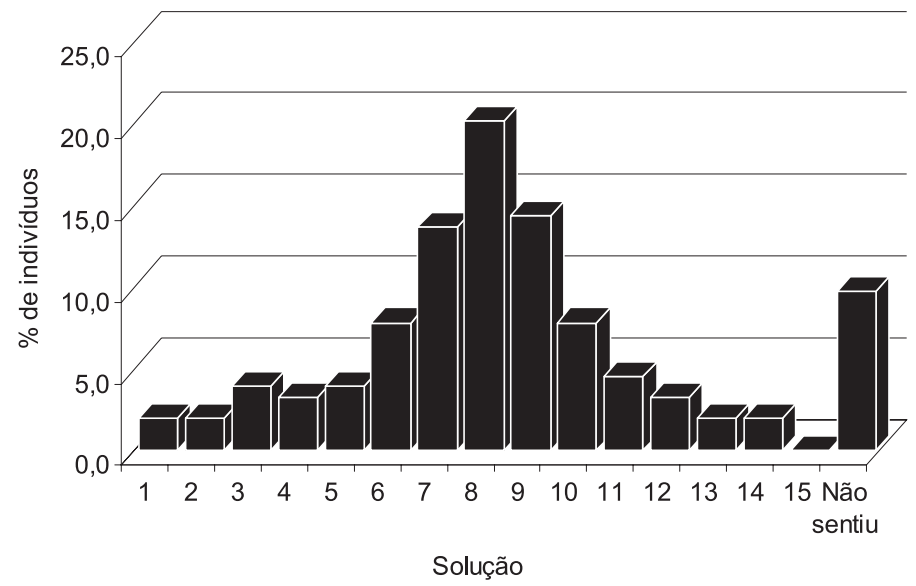

Neste estudo constatou-se ainda que, 9,7\% $(\mathrm{n}=15)$ dos participantes eram insensíveis. Não houve diferença significativa entre o número de homens e mulheres insensíveis à feniltiocarbamida, e obteve-se também a frequência alélica do alelo recessivo 0,31 .

Em relação ao tabagismo, apenas $5,8 \%$ dessa população era fumante. A relação entre indivíduos fumantes, gripados e a capacidade de sentir o gosto da proteína não foi significativa. Pois, apenas um indivíduo (6,7\%) que não sentiu o gosto da feniltiocarbamida era fumante, e um outro (6,7\%) que também não sentiu, estava com sinusite. Aproximadamente $90 \%$ dos indivíduos que não sentiram o gosto amargo não apresentavam nenhuma das características anteriormente citadas. Não houve diferença entre as preferências alimentares listadas no questionário. 
Ao realizar a prática de sensibilidade à feniltiocarbamida, foi observado que os participantes esperavam o momento em que os colegas sentiam ou não o gosto para que pudessem comparar ao seu limiar gustativo, o que demonstra a interação promovida pela prática, além de comprovar o interesse deles na temática abordada.

Notou-se que, para os alunos da EJA, a prática parecia mais distante da sua realidade, pois ao relatar fatos associados a conceitos genéticos explicitados por características do próprio indivíduo, os alunos ficavam surpresos com a correlação, possivelmente por estarem acostumados a não terem tanto contato com questões científicas e complexas a não ser por meio de televisão, jornal e rádio.

\section{Discussão}

O maior número de mulheres encontrado na instituição de ensino superior, $72,9 \%$, corrobora estudos da literatura que constataram um número superior de indivíduos do sexo feminino em cursos como Medicina, seguido pelos de Biologia e Biomedicina (SCHIEBINGER, 2008). Além do mais, os anos de estudos das mulheres superam os dos homens (ROSEMBERG, 2001), sendo cada vez mais crescente, a presença delas em universidades (MELO; RODRIGUES, 2006).

$\mathrm{Na}$ escola de ensino médio, o número de professores e professoras participantes foi praticamente igual, e o mesmo sendo aplicado aos estudantes da EJA. Essas informações corroboram os dados da Associação Brasileira de Educação a Distância - ABED (2008), os quais afirmam que a diferença no número de mulheres e homens nesse tipo de ensino não é significativa. Baseando-se nos parâmetros educacionais do país, esses dados contradizem todo o antigo histórico da educação, nos quais as mulheres eram designadas à criação dos filhos e ao bem estar familiar, deixando a educação em segundo plano. Ressalta-se ainda que atualmente homens e mulheres, mesmo com uma rotina corrida, muitos são trabalhadores casados(as), domésticas, ex-presidiários(as), seguranças noturnos, encontram-se nos mesmos parâmetros educacionais, caracterizando a realidade dos alunos da EJA. 
O grande número de participantes com idades entre 18 a 20 anos comprova que os alunos estão entrando cada vez mais cedo no ensino superior, e isso também se aplica àqueles da EJA que, mesmo em defasagem escolar, não deixam de concluir o ensino médio nessa fase da vida.

O baixo número de fumantes nos cursos de nível superior $(\mathrm{n}=6)$ era previsto conforme estudos de Nascimento e Rodrigues (2008), cujos dados enfatizam esse baixo nível de fumantes nos cursos superiores.

Em relação aos fumantes sensíveis à feniltiocarbamida, o resultado demonstrou que, ainda que estudos comprovem o efeito nocivo da nicotina sobre as papilas gustatórias (PARKER; DOUCET, 1995), isso não se aplica a todos os fumantes, sendo que, apenas um participante $(6,7 \%)$ - fumante - não sentiu o amargo da feniltiocarbamida, o que corrobora estudos que contradizem essa hipótese (COMPTON et al., 2007).

Ao final deste estudo, apenas uma pessoa que estava com sinusite não sentiu o gosto da feniltiocarbamida, porém, não podemos deixar de relatar que a percepção de pessoas sensíveis e gripadas pode ter sido observada em solução com maiores gradientes de concentração da proteína, do que poderia ter sido se a pessoa não estivesse nessas condições.

Era esperado que a sensibilidade ao PTC se concentrasse na faixa das soluções 06 a 10, conforme análises de populações mundiais relatadas por Saldanha (1958) e Caraballo, Rebato e Basabe (1984). A concentração de sensibilidade a feniltiocarbamida na solução 08 já foi constatada em estudos anteriormente efetuados com a população de Brasília (MORAIS et al., 2007), por isso, é possível que esse seja um padrão de sensibilidade à feniltiocarbamida nessa população. Entretanto, novos estudos devem ser realizados a fim de confirmar esse dado, uma vez que, essa percepção varia de população para população e o número amostral de indivíduos foi significantemente pequeno.

A porcentagem de indivíduos sensíveis deste estudo, 90,3\%, se aproxima do resultado obtido por Aguirre e Scrimshaw (1956) realizado em uma população indígena guatemalteca, composta por 385 pessoas, sendo 99,20\% delas sensíveis a feniltiocarbamida.

Entre os indivíduos que não sentiram o gosto, a diferença entre sexo não foi relevante, sete mulheres e oito homens o que reforça o padrão de herança au- 
tossômica. A frequência alélica obtida para o alelo recessivo, 0,31, se aproxima da frequência alélica da população chinesa, 0,32 (BARCONIT, 1950 apud SALDANHA, 1958) e negra brasileira, 0,33 (KALMUS, 1957 apud SALDANHA, 1958).

A não relação entre a sensibilidade ao PTC e aos alimentos listados, contradiz dados que afirmam que, o quanto mais sensível à feniltiocarbamida o indivíduo for maior é sua tendência de rejeitar alimentos que contenham essa proteína (DREWNOWSKI et al., 2001; MORAIS et al., 2007). Contudo, é possível que essa relação não tenha sido observada devido ao pequeno número da população amostral.

Neste trabalho, pôde-se observar a curiosidade dos participantes em entender porque uns sentiam o gosto amargo e outros não. Nesse contexto, esse interesse dos participantes comprova a finalidade da prática, que além de promover a interação e instigá-los a entender como se aplica a teoria no cotidiano, despertou o senso crítico e facilitou o entendimento das bases conceituais envolvidas nessa dinâmica.

\section{Conclusão}

Práticas como a de sensibilidade à feniltiocarbamida, abragem inúmeros conceitos de genética, uma vez que auxiliam a demonstrar o tipo de herança mendeliana envolvida, a efetuar cálculos de probabilidade e levantar hipóteses sobre como fatores de seleção naturais e evolutivos inferem ao longo do tempo sobre diferentes populações.

Os resultados obtidos da prática, como a diferença entre o número de fumantes e não fumantes, além do número de homens e mulheres que frequentam centros educacionais, auxiliaram os participantes a compreenderem não só os aspectos teóricos dessa dinâmica, mas também, os aspectos socioculturais.

Contudo, mesmo que estudos moleculares referentes ao polimorfismo da PTC esclareçam o verdadeiro genótipo de cada indivíduo, em sala de aula, o teste de sensibilidade à feniltiocarbamida não tem como objetivo identificar esses genótipos, mas sim, auxiliar os participantes a vivenciarem esses conceitos genéticos, fazendo dessa dinâmica um meio de aproximação da realidade, rompendo a distância existente entre a população leiga e a Genética. 


\section{The bitter taste used like a pedagogical practical for genetic study}

\section{Abstract}

Genetics studies are always a challenge for teachers. The objective of this project was to approach genetic conceptual basis to people's quotidian, using phenylthiocarbamide test as a pedagogical practice. The phenylthiocarbamide dilution, in fifteen solutions with decreasing gradients of concentration, was prepared as Fox (1932). The practice was developed in two schools and 154 participants were included. From these, 5.2\% were smokers, and 90.3\% were sensitive to phenylthiocarbamide. The perception to bitter taste was concentrated between solutions seven, eight and nine, with $48 \%$ of the participants, but in solution eight the majority (20.15\%) felt the bitter taste of the protein. No one showed sensitivity to phenylthiocarbamide in solution fifteen. For the population in study the frequency of recessive (nontaster) allele is 0.31 . No relation between smoking people, sickness and the ability to taste the PTC was found.

Keywords: Protein. Polymorphism. Bitter taste. Education.

\section{Referências}

ABED. Números do EJA são divulgados pelo Inep. Disponível em: $<$ http://www2. abed.org.br/noticia.asp?Noticia>_ID=135>. Acesso em: 03 nov. 2008.

AGUIRRE, F.; SCRIMSHAW, N. S. Ability of representative groups of guatemalan indians to taste phenylthiourea. Records of the Genetics Society of America, [S.l.], v. 25, n. 631, p. 215, 1956.

BERNARDES, T. A. O uso de atividade lúdica no ensino de genética na escola. 2007. Trabalho de conclusão de curso (Licenciatura em Biologia)- Centro Universitário de Brasília, Brasília, 2007.

CAMARGO, S. S.; INFANTE-MALACHIAS, M. E. A genética humana no ensino médio: Algumas Propostas. Genética na Escola, [S.l.], v. 2, n. 1, p. 14-16, 2007.

CARABALlO, C.; REBATO, E.; BASABE, J. M. Estudio comparativo de la sensibilidad gustativa a la feniltiocarbamida (P.T.C.) en las poblaciones vasca autóctona, mixta y foránea. Cuardenos de Antropología-Etnografía, Zainak, v. 2, p.313-318, 1984. 
COMPTON, M. T. et al. Lack of support for the inability to taste phenylthiocarbamide as an endophenotypic marker in patients with schizophrenia and their first-degree relatives. Schizophrenia Research, [S.1.], v.95, p. 65-69, 2007.

DREWNOWSKI, A. et al. Genetic taste markers and food preferences. Drug Metabolism and Disposition, [S.1.], v. 29, n. 4, p. 535-538, 2001.

FOX, A. F. The relationship between chemical constitution and taste. Proc Natl Acad Sci, [S.1.], v. 18, p. 115-120, 1932.

KARAM-JUNIOR, E. Estudos sobre um marcador genético de percepção e alguns traços relacionados à lateridade em pacientes com distúrbios mentais. 1975. Dissertação (Pós-Graduação em Genética) - Universidade Federal do Paraná, Curitiba, 1975.

KIM, U. et al. Positional cloning of the human quantitative trait locurs underlying taste sensitivity to phenylthiocarbamide. Science, [S.1.], v.229, n. 5610, p. 1221-1225, 2003.

KIM, U. et al. Variation in the human TAS1R taste receptor genes. Chemical Senses, [S.1.], v. 31, n. 7, p. 599-611, 2006.

MELO, H. P.; RODRIGUES, L. M. C. S. Mulheres e ciência: uma história necessária. Estudos Feministas, [S.1.], v. 14, n. 3, p. 819-820, 2006.

MERRITT, R. B. et al. Tasting phenylthiocarbamide (PTC): a new integrative genetics lab with an old flavor. The American Biology Teacher, [S.1.], v. 75, n. 1, p. 23-28, 2008.

MOBERG, P. J. et al. Phenylthiocarbamide (PTC) perception in parkison disease. Cognitive and Behavioral Neurology, [S.1.], v. 20, n. 3, p. 145-148, 2007.

MOBERG, P. J. et al. Phenylthiocarbamide perception in patients with schizophrenia and first-degree family members. The American Journal of Psychiatry, [S.1.], v. 162, p. 788-790, 2005.

MORAIS, J. R. S. et al. Relação da sensibilidade à feniltiocarbamida (PTC) e o estado nutricional dos pacientes atendidos em um centro de saúde de Brasília - DF. Revista Brasileira de Obesidade, Nutrição e Emagrecimento, [S.1.], v. 1, n. 1, p. 72-79, 2007.

NASCIMENTO, P. P; RODRIGUES, A. J. L. Perfil dos alunos do curso ciências biológicas da UNUCET quanto ao conhecimento dos fatores de risco e 
prevenção contra o câncer. Disponível em: <http://www.prp.ueg.br/06v1/ctd/ dstq/outros/ ds_20050701_001.pdf>. Acesso em: 10 nov. 2008.

PARKER, L. A.; DOUCET, K. The effects of nicotine and nicotine withdrawal on taste reactivity. Pharmacology, Biochemistry, and Behavior, [S.1.], v. 52, n. 1, p. 125-129, 1995.

RAMALHO, M. A. P. et al. Ajudando a fixar os conceitos de genética. Genética na Escola, [S.1.], v. 1, n. 2, p. 45-49, 2006.

ROSEMBERG, F. Educação formal, mulher e gênero no Brasil contemporâneo. Estudos Feministas, [S.1.], v. 9, n. 2, p. 515 -540, 2001.

SALDANHA, P. H. Taste thresholds for phenylthiourea among japanese. Annals of Human Genetics, [S.l.], v. 22, n. 4, p. 380-384, 1958.

SCHIEBINGER, L. Mais mulheres na ciência: questões de conhecimento. História, Ciências, Saúde, Manguinhos, v. 15, p. 269-281, 2008.

VILAS-BOAS, A. Conceitos errôneos de genética em livros didáticos do ensino médio. Genética na Escola, v. 1, n. 1, p. 9-11, 2006.

WHITTEMORE, P. B. Phenylthiocarbamide (PTC) tasting and reported depression. Journal of Clinical Psychology, [S.1.], v. 42, n. 2, p. 260-263, 1986.

WOODING, S. et al. natural selection and molecular evolution in PTC, a bittertaste receptor gene. American Journal of Human Genetics, [S.l.], v. 74, n. 4, p. 637-646, 2004.

WOODING, S. Phenylthiocarbamide: a 75-year adventure in genetics and natural selection. The Genetics Society of American, [S.l.], v. 172, p. 2015-2023, 2006. 


\section{Anexo A: Questionário aplicado durante a prática}

UniCEUB - Faculdade de Ciências da Educação e Saúde (FACES)

Projeto de Pesquisa: Compreendendo genética através do teste de sensibilidade à feniltiocarbamida (PTC).

Responsáveis: Profa . Dra ${ }^{a}$. Fernanda Vinhaes de Lima - fvlima@brturbo. com e Ingrid de Souza Freire - ingridbiomol@gmail.com

1. Sexo ( ) F ( ) M

2. Idade?

3. Fumante? ( ) não ( ) sim

4. Você está gripado ou com alguma doença que possa influenciar seu paladar?

( ) não ( ) sim. Qual?

5. Em qual solução você percebeu o sabor amargo da proteína feniltiocarbamida? Marque um X na solução correspondente.
( ) Sol. 01
( ) Sol. 09
( ) Sol. 02
( ) Sol. 10
( )Sol. 03
( ) Sol. 11
( ) Sol. 04
( ) Sol. 12
( ) Sol. 05
( ) Sol. 13
( ) Sol. 06
( ) Sol.14
( ) Sol. 07
( ) Sol. 15
( ) Sol. 08
( ) Não senti nada

6. Quais dos alimentos seguintes você gosta ou não gosta? Responda com "G" para os de que gosta, e "NG" para os de que não gosta.
( ) couve
( ) brócolis
( ) vinho tinto
( ) chá verde ( ) cerveja
( ) couve-flor
( ) café
( ) repolho
( ) pimenta
( ) nabo
( ) rabanete
( ) agrião
( ) couve-de-bruxelas
( ) queijo branco (minas ou frescal)
( ) queijo amarelo (cheddar, emmental, prato) 